\title{
An analysis of the dynamics of change in the number of tourists who used Polish hotel services in the years 2009-2015
}

\section{Pawel Luka ${ }^{1}$}

\begin{abstract}
The aim of this study is an analysis of the dynamics of change in the number of tourists who used Polish hotel services in the years 2009-2015. For this evaluation data from the Central Statistical Office of Poland were used. The obtained data pertaining to the number of both Polish and foreign tourists were analysed in an absolute and a relative (percentage) scale. The results shown in a relative scale provide a better picture of the dynamics of change in the processes as all values are assigned an initial value: $P_{0}=100$ percent. They therefore informs what was the dynamics of growth in the initial 100 tourists who used Polish hotel services in the years 2009-2015.
\end{abstract}

Keywords: Hospitality, accommodation, dynamics, overnight visitor

To cite this article: Luka, P.. (2017). An analysis of the dynamics of change in the number of tourists who used Polish hotel services in the years 2009-2015. Journal of Tourism Theory and Research, 3(1), 1-8. DOI: 10.24288/jttr.279174

\footnotetext{
${ }^{1}$ Department of Tourism and Recreation, University of Rzeszow, Poland, pavelluka@gmail.com
} 


\section{Introduction}

Over the recent years, tourism has experienced continued growth, becoming one of the fastest growing economic sectors in Poland. This important economy sector not only generates economic growth and development, but it also creates various social benefits. It makes employment opportunities by creating new jobs in hospitality, gastronomy and transport businesses. The term "tourism" is used here in a very broad sense, and also includes all sorts of expenses connected with the departures and arrivals of visitors. Because of the complex nature of tourism, to analyse it one needs various sources of statistical data and the right methodological tools.

This study is based on data from the latest edition of Tourism in 2015 Survey published by Central Statistical Office in Poland (2016). This is the source of data on capacity and occupancy in tourist accommodation establishments, participation of Polish and overseas residents in tourism and on border traffic. Information is obtained through the reports of the capacity and occupancy in tourist accommodation establishments in each year (Central Statistical Office, 2015, 2016).

The reporting units provide the following: precise location, type and category of the establishment, number of rooms, beds and catering establishments. Furthermore, they provide information on the establishment occupation in individual months. i.e. on the number of days of the establishment activity, nominal number of bed places or rooms, as well as the number of persons accommodated, and the number of overnight stays and rented rooms (separately for Polish and foreign tourists).

On 31 July 2015, there were 10024 registered tourist accommodation establishments in Poland, out of which 6845 operated all year round. Altogether there were 20 types of lodging facilities, with 3723 being hotel and similar establishments and the remainder 6301 falling into the rest of the categories. Amongst hotel type lodging facilities, hotels were the largest group - 2316, while the largest group in the other categories were rooms for guests -1876 . In the all lodging facilities there were 710,3 thousands bed places available. Traditionally, the most bed places were available in hotels - 235,6 thousands, which made up 33,2 percent of all bed places available as of 31 July 2015 In 2015, as compared to the results of the 2014 Survey, the number of all lodging facilities and available bed places have increased respectively by 1,4 percent and 0,02 percent (Central Statistical Office, 2015, 2016).

Tables 1.1. and 1.2. present hotels in Poland by category, including the number of facilities and the number of bed places for the years 2009-2015 (see figures 1.1. and 1.2.) A general increase in the number of hotels was observed during this period. However, this increase was particularly dynamic starting from 2009. Especially, a considerable rise in the number of 3-star and 4-star hotels contributed to this phenomenon. Moreover, among the total number of hotels, apart from those that were remained in their categories, there was a certain number of hotels which were in the process of categorization. Although this number was gradually decreasing, it rose slightly in the period 2014-2015. The number of bed places in Polish hotels also increased. In 2015, as compared to 2009, the number of hotel facilities and the number of bed places in those hotels increased respectively by 41,7 percent and 42,3 percent. If we compare 2014 and 2015 , these numbers are 2,9 percent for the number of hotel facilities and 3,6 percent for the number of bed places.

Table 1.1. Hotels by category - facilities

\begin{tabular}{|c|c|c|c|c|c|c|c|}
\hline Hotels & 2009 & 2010 & 2011 & 2012 & 2013 & 2014 & 2015 \\
\hline Total & 1634 & 1796 & 1883 & 2014 & 2107 & 2250 & 2316 \\
\hline$* * * * *$ & 35 & 43 & 45 & 47 & 47 & 55 & 57 \\
\hline$* * * *$ & 141 & 162 & 180 & 224 & 261 & 303 & 321 \\
\hline$* * *$ & 676 & 779 & 845 & 910 & 964 & 1056 & 1108 \\
\hline$* *$ & 487 & 510 & 518 & 551 & 565 & 572 & 565 \\
\hline$*$ & 175 & 177 & 174 & 177 & 171 & 167 & 158 \\
\hline During categorization & 120 & 125 & 121 & 105 & 99 & 97 & 107 \\
\hline
\end{tabular}

Source: Own work based on data of the Central Statistical Office (2016) 
Table 1.2. Hotels by category - bed places (in thousands)

\begin{tabular}{|c|c|c|c|c|c|c|c|}
\hline Hotels & 2009 & 2010 & 2011 & 2012 & 2013 & 2014 & 2015 \\
\hline Total & 165,6 & 176,0 & 187,0 & 198,1 & 208,6 & 227,5 & 235,6 \\
\hline$* * * * *$ & 10,0 & 10,8 & 10,8 & 11,9 & 11,3 & 13,0 & 14,0 \\
\hline$* * * *$ & 27,6 & 33,7 & 38,6 & 47,6 & 53,5 & 62,0 & 65,1 \\
\hline$* * *$ & 70,2 & 73,7 & 78,0 & 81,4 & 85,5 & 93,2 & 100,0 \\
\hline$* *$ & 37,8 & 38,4 & 39,1 & 39,6 & 41,0 & 41,2 & 38,6 \\
\hline * & 12,2 & 11,9 & 12,0 & 11,9 & 11,6 & 12,1 & 11,7 \\
\hline During categorization & 7,8 & 7,6 & 8,6 & 5,8 & 5,7 & 6,1 & 6,2 \\
\hline
\end{tabular}

Source: Own work based on data of the Central Statistical Office (2016)

Figure 1.1. Hotels by category - facilities

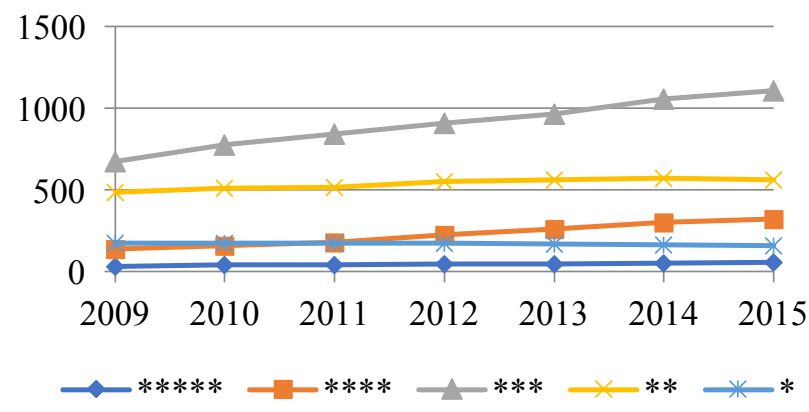

Source: Own work based on data of the Central Statistical Office (2016)
Figure 1.2. Hotels by category - bed places (in thousands)

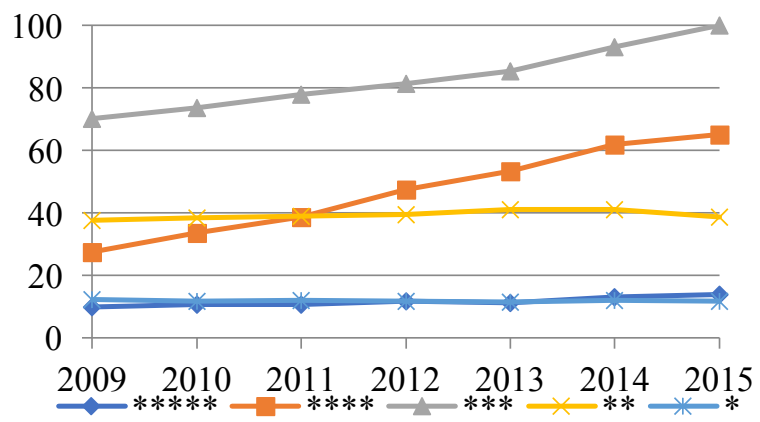

Source: Own work based on data of the Central Statistical Office (2016)

Table 1.3. The number of Polish and foreign tourists who stayed in Polish hotels in the years 2009-2015 (in thousands)

\begin{tabular}{|c|c|c|c|}
\hline Year & Tourists in total & Polish tourists & Foreign tourists \\
\hline 2009 & 10641,8 & 7500,3 & 3141,5 \\
\hline 2010 & 11739,9 & 8355,5 & 3384,4 \\
\hline 2011 & 12721,6 & 9129,1 & 3592,5 \\
\hline 2012 & 13461,3 & 9439,1 & 4022,2 \\
\hline 2013 & 14568,2 & 10246,0 & 4322,3 \\
\hline 2014 & 16138,3 & 11616,4 & 4521,9 \\
\hline 2015 & 17487,1 & 12779,4 & 4707,7 \\
\hline
\end{tabular}

Source: Own work based on data of the Central Statistical Office (2016)

Table 1.3. presents the breakdown of hotel overnight visitors sourced from the Tourism in 2015 Survey, for the years 2009-2015.

In the year 2015, 17,5 million tourists (residents and non-residents) stayed in hotels in Poland, 8,4 percent increase compared with the year 2014. This follows an increase of 10,8 percent in the year 2014 and an increase of 8,2 percent in the year 2013. During the period from the year 2009 to 2015 , total tourists number rose by 64,3 percent. The percentage increase in domestic guests (70,4 percent) has exceeded that of international $(49,9$ percent) for the last six years.

\section{Methods}

The aim of this analysis is evaluation of the dynamics of change in the number of Polish residents and non-residents who stayed in Polish hotel establishments in the years 2009-2015. In this study, empirical data published by the Central Statistical Office of Poland $(2015,2016)$ were used. 
Symbols used in this study:

$t$ - time expressed in appropriate units, e.g. years;

$J_{t}$ - general symbol for a value in time $t$, expressed in an absolute scale, in time series considered to be discrete time series (for example the general number of tourists who used hotel services in year $t$ );

$J_{0}$ - initial value in time $t$ (value in the year 2009), in an absolute scale, in discrete time series, $t=0$;

$J_{k}$ - final value in time $t$ (value in the year 2015), expressed in an absolute scale, in discrete time series;

$M_{t}$ - general symbol for a value in time $t$, expressed in an absolute scale, in continuous time series;

$M_{0}$ - initial value in time $t$, (value in the year 2009), in continuous time series, $t=0$;

$M_{k}$ - final value in time $t$, (value in the year 2015), in continuous time series;

$P_{t}$ - value in time $t$, expressed in a relative scale, where $P_{0}=100 \%$, percentage values are obtained through a linear transformation of the $M_{t}$ value. $P_{t}$ informs us about an increase or a decrease in the initial 100 units of the value, it is a normalised scale;

$P_{0}$ - initial value in time $t$, (value in the year 2009), expressed in a relative (percentage) scale, $P_{0}=100 \%$;

$P_{k}$ - final value in time $t$, (value in the year 2015), expressed in a relative (percentage) scale;

$P_{K}$ - relative (percentage) change of a final value of a time series as in regard to the initial value (eg. $M_{k}$ to $M_{0}$, where $M_{0}=100 \%$ ).

The empirical data on the number of resident and non-resident tourists who used Polish hotel services in the years 2009-2015, as shown in table 1.3., primary are marked with set $J_{t}$, where $t$ is the time given in years from 2009 to 2015. They are of a discrete nature. Data in this form do not allow to evaluate the dynamics of change (Łuka, 2007; Łuka, KwiatkowskaSienkiewicz, 2010a, 2010b; Stokłosa, 2004, 2006). Therefore, they were transformed into continuous time series $M_{t}$, by adding up consecutive sets according to the formula (2.1.):

$$
M_{t}=\sum_{t=0}^{t} J_{t} \text {, and } J_{t}=M_{t}-M_{t-1}
$$

The $M_{t}$ values inform how many resident and nonresident overnight visitors, as well as how many tourists in total had used Polish hotels during a given period of time $t$. Thus, the $M_{t}$ sets show how the number of people who used the hotel services changed on a long-term scale. They allow to estimate the dynamics of change in the examined processes on an absolute scale for consecutive years. In order to estimate this dynamics also on a relative scale the sets were subjected to a linear conversion into a relative (percentage) scale $P_{t}$, according to the following formula (2.2.):

$$
P_{t}=\frac{M_{t} \cdot 100}{M_{0}}[\%],
$$

where: $\quad P_{0}=100 \%$,

$M_{0}>0$,

$M_{0}$ - the initial value of the set,

$M_{t}$ - the value in time $t$.

On the $P_{t}$ scale all sets are assigned the initial value $P_{0}=100 \%$. Likewise, the discrete $J_{t}$ sets were converted into a percentage scale $P_{t}[\%]$ according to the formula (2.3.):

$$
P_{t}=\frac{J_{t} \cdot 100}{J_{0}}[\%],
$$

where: $\quad P_{0}=100 \%$,

$J_{0}>0$,

$J_{0}$ - the initial value of the set,

$J_{t}$ - the value in time $t$.

$P_{t}$ series allow for the most accurate comparison of the dynamics. They show with what dynamics the number of the initial 100 tourists grew in Poland in the years 2009-2015. To compare different dynamics it is necessary to start with the same initial value of the compared processes. And in this purpose that the relative percentage scale $P_{t}$ is so well suited for (Stokłosa, 2004, 2006).

Two definitions of dynamics are used in this study: an absolute one for the $M_{t}$ sets and a relative (specific) one for the $P_{t}$ sets. Absolute dynamics is defined as the changes in momentary velocity and momentary acceleration on a precisely defined path of the process. 
Relative dynamics, on the other hand, is defined by the changes in specific momentary velocity and specific momentary acceleration on a precisely defined path of the process. The path of a given process is the mechanism of an elementary event, repeated over and over in time, and in effect a cause-and-effect descriptive function which takes into account the elementary mechanism (Abraham-Frois, 2002; Kondratowicz-Pietruszka, Stokłosa, 1994).

All $J_{t}$ sets, the obtained $M_{t}$ sets and the calculated sets of percentages $P_{t}$ for both discrete and continuous series are presented in table 3.1., which also contains the values of the $P_{K}$ [\%] parameter calculated according to formulas (2.4.), (2.5.) and (2.6.):

for discrete sets $J_{t}$ :

$$
P_{K}=\frac{J_{k} \cdot 100}{J_{0}}[\%]
$$

where: $\quad J_{0}>0$,

$$
\begin{aligned}
& J_{0} \text { - the initial value, } \\
& J_{0} \text { - the final value; }
\end{aligned}
$$

for continuous sets $M_{t}$ :

$$
P_{K}=\frac{M_{k} \cdot 100}{M_{0}}[\%]
$$

where: $\quad M_{0}>0$,

$$
\begin{aligned}
& M_{0}-\text { the initial value, } \\
& M_{k}-\text { the final value; }
\end{aligned}
$$

for discrete and continuous sets $P_{t}$ :

$$
P_{K}=\frac{P_{k} \cdot 100}{P_{0}}[\%]
$$

where: $\quad P_{0}>0$,

$$
\begin{aligned}
& P_{0}-\text { the initial value, } \\
& P_{k}-\text { the final value. }
\end{aligned}
$$

The $P_{K}$ values show what percentage of the initial $(100 \%)$ value the final value is. The $P_{K}$ values are not appropriate for assessing the dynamics of processes. However, they provide interesting information on the changes of the value at the end of the process compared with the initial value at the one set of the process (Kondratowicz-Pietruszka, Stokłosa, 1994). The results of the above calculations are presented in tables 3.1. and 3.2.

\section{Results and discussion}

As one can see, table 3.1. contains discrete empirical data referring to the total number of tourists who stayed in Polish hotels in the years 2009-2015. They have been assigned the symbol $J_{t}$. It also presents the values of this process converted linearly into continuous sets - they are marked with the symbol $M_{t}$. Moreover, it also contains the relative values (percentages) $P_{t}$ for both discrete $J_{t}$ and continuous $M_{t}$ series. Additionally, for every set in an absolute and a relative scale, the table provides the calculated changes of the final values as compared with the initial values $\left(P_{K}\right)$. Using the data from table 3.1., figures 3.1. and 3.2. were created. They show the total number of tourists who used hotel services in Poland in the years 2009-2015 and the dynamics of changes in the total number of visitors who stayed in hotels in Poland in those years.

Table 3.1. The total number of tourists who stayed in Polish hotels in the years 2009-2015

\begin{tabular}{|c|c|c|c|c|c|}
\hline Year & $\boldsymbol{t}$ & $\begin{array}{c}\boldsymbol{J}_{\boldsymbol{t}} \\
\text { [thousands] }\end{array}$ & $\begin{array}{c}\boldsymbol{P}_{\boldsymbol{t}} \\
{[\mathbf{\%}]}\end{array}$ & $\begin{array}{c}\boldsymbol{M}_{\boldsymbol{t}} \\
\text { [thousands] }\end{array}$ & $\begin{array}{c}\boldsymbol{P}_{\boldsymbol{t}} \\
{[\%]}\end{array}$ \\
\hline 2009 & 0 & 10641,8 & 100,0 & 10641,8 & 100,0 \\
\hline 2010 & 1 & 11739,9 & 110,3 & 22381,7 & 210,3 \\
\hline 2011 & 2 & 12721,6 & 119,5 & 35103,4 & 329,9 \\
\hline 2012 & 3 & 13461,3 & 126,5 & 48564,6 & 456,4 \\
\hline 2013 & 4 & 14568,2 & 136,9 & 63132,9 & 593,3 \\
\hline 2014 & 5 & 16138,3 & 151,7 & 79271,2 & 744,9 \\
\hline 2015 & 6 & 17487,1 & 164,3 & 96758,3 & 909,2 \\
\hline $\boldsymbol{P}_{\boldsymbol{K}}[\mathbf{\%}]$ & & 164,3 & 164,3 & 909,2 & 909,2 \\
\hline
\end{tabular}

Source: Own study based on data of the Central Statistical Office (2016) 
Figure 3.1. The number of tourists who stayed in Polish hotels in the years 2009-2015 - $J_{t}$ values (in thousands)



Source: Own study based on table 3.1.

The total number of tourists who used Polish hotel services in the years from 2009 to 2015 grew with the passage of time, which means that there was a general increase in the value $\left(P_{K}=164\right.$ percent). It was a gradual process of a rather slow dynamics. During the period from the year 2010 and 2012 the velocity of the process went down, while in the years 2012-2014, it clearly increased, and then in the years 2014-2015 it dropped again. It is also worth noting that in the years 2012-2014 the increase of the velocity value was
Figure 3.2. The dynamics of change in the number of tourists who stayed in Polish hotels in the years 2009-2015 $-M_{t}$ values (in thousands)

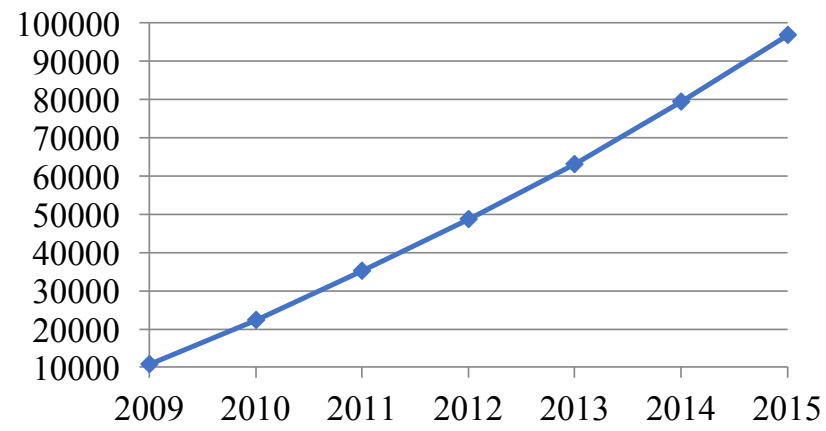

Source: Own study based on table 3.1.

relatively large, while and in 2014 it was the largest 10,8 percent (table 3.1., figures: 3.1 . and 3.2.).

When comparing the discrete sets $J_{t}$ with the continuous sets $M_{t}$, both of which refer to the numbers of tourists who used Polish hotel services, one can clearly notice that the picture of a continuous process is a far better way of presenting a trend over time (figures: 3.1. and 3.2).

Table 3.2. The dynamics of change in the number of tourists who stayed in Polish hotels in the years 20092015

\begin{tabular}{|c|c|c|c|c|c|c|c|c|c|}
\hline \multirow[b]{2}{*}{ Year } & \multirow[b]{2}{*}{$t$} & \multicolumn{4}{|c|}{ Polish tourists } & \multicolumn{4}{|c|}{ Foreign tourists } \\
\hline & & $\begin{array}{c}J_{t} \\
\text { [thou- } \\
\text { sands] }\end{array}$ & $\begin{array}{l}P_{t} \\
{[\%]}\end{array}$ & $\begin{array}{c}M_{t} \\
\text { [thou- } \\
\text { sands] }\end{array}$ & $\begin{array}{l}P_{t} \\
{[\%]}\end{array}$ & $\begin{array}{c}J_{t} \\
\text { [thou- } \\
\text { sands] }\end{array}$ & $\begin{array}{l}P_{t} \\
{[\%]}\end{array}$ & $\begin{array}{c}M_{t} \\
\text { [thou- } \\
\text { sands] }\end{array}$ & $\begin{array}{l}P_{t} \\
{[\%]}\end{array}$ \\
\hline 2009 & 0 & 7500,3 & 100,0 & 7500,3 & 100,0 & 3141,5 & 100,0 & 3141,5 & 100,0 \\
\hline 2010 & 1 & 8355,5 & 111,4 & 15855,8 & 211,4 & 3384,4 & 107,7 & 6525,9 & 207,7 \\
\hline 2011 & 2 & 9129,1 & 121,7 & 24984,9 & 333,1 & 3592,5 & 114,4 & 10118,5 & 322,1 \\
\hline 2012 & 3 & 9439,1 & 125,8 & 34423,9 & 459,0 & 4022,2 & 128,0 & 14140,7 & 450,1 \\
\hline 2013 & 4 & 10246,0 & 136,6 & 44669,9 & 595,6 & 4322,3 & 137,6 & 18463,0 & 587,7 \\
\hline 2014 & 5 & 11616,4 & 154,9 & 56286,3 & 750,5 & 4521,9 & 143,9 & 22984,9 & 731,7 \\
\hline 2015 & 6 & 12779,4 & 170,4 & 69065,7 & 920,8 & 4707,7 & 149,9 & 27692,6 & 881,5 \\
\hline $\begin{array}{r}P_{K} \\
{[\%]}\end{array}$ & & 170,4 & 170,4 & 920,8 & 920,8 & 149,9 & 149,9 & 881,5 & 881,5 \\
\hline
\end{tabular}

Source: Own study based on data of the Central Statistical Office (2016) 
Figure 3.3. The number of Polish and foreign tourists who stayed in Polish hotels in the years 2009$2015-J_{t}$ values (in thousands)

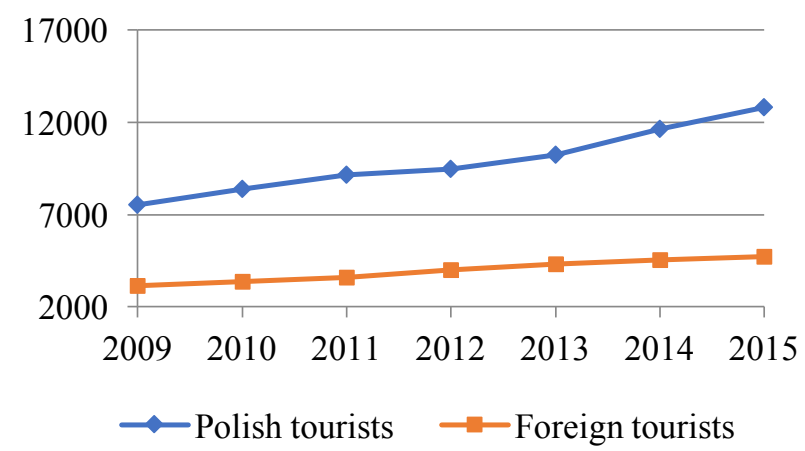

Source: Own study based on table 3.2.

Figure 3.4. A comparison of the dynamics of change in the number of Polish and foreign tourists who stayed in Polish hotels in the years 2009-2015 $M_{t}$ values (in thousands)

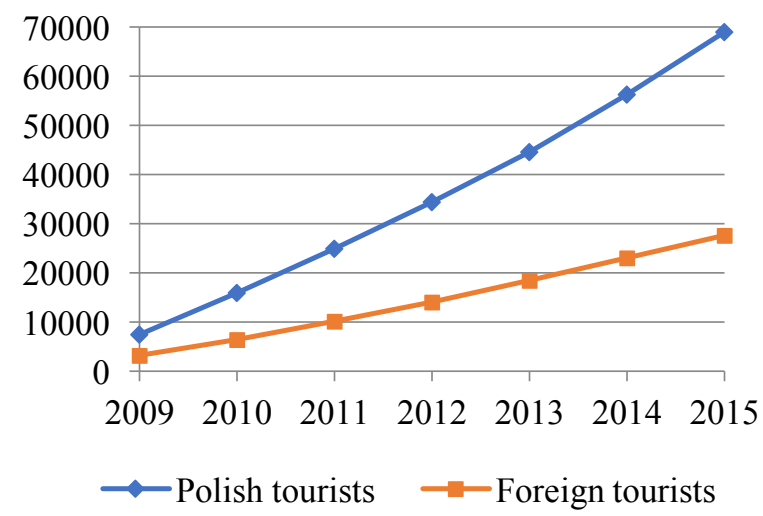

Source: Own study based on table 3.1.

Figure 3.3. presents the number of Polish and foreign tourists who used Polish hotel services in the years 2009-2015. All values are given in discrete sets $\left(J_{t}\right)$, in an absolute scale. Figure 3.4. presents the dynamics of change in the number of Polish and foreign tourists in the same period of time. These values are also given in an absolute scale, in $M_{t}$ sets ,which are considered to be continuous. Figures 3.5. and 3.6. present the same changes in the number of Polish and foreign tourists who used Polish hotel services in the years 2009-2015 for both discrete and continuous sets in percentages $\left(P_{t}\right)$.

In the years 2009-2015, the number of Polish and foreign tourists who stayed in Polish hotel establishments increased. For both of them, a general increase was observed $\left(P_{K}>100 \%\right)$. In the case of
Figure 3.5. The number of Polish and foreign tourists who stayed in Polish hotels in the years 20092015 for discrete sets $\left(J_{t}\right)$ - values in $P_{t}$ scale (\%)

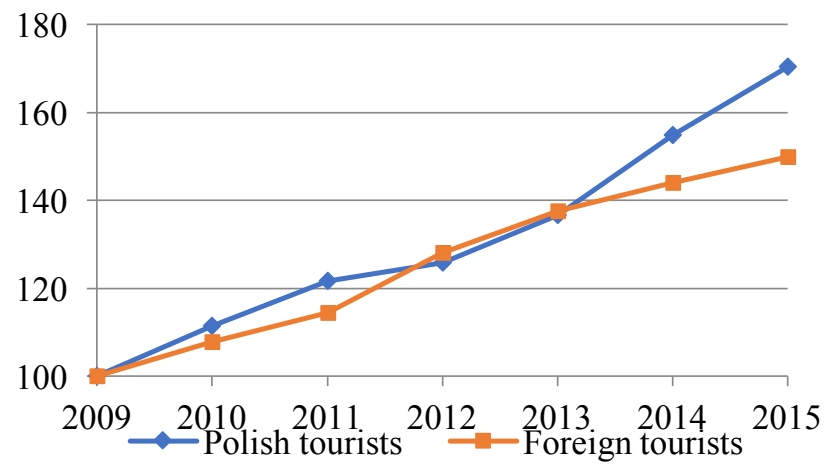

Source: Own study based on table 3.2.

Figure 3.6. A comparison of the dynamics of change in the number of Polish and foreign tourists who stayed in Polish hotels in the years 2009-2015 for continuous sets $\left(M_{t}\right)$ - values in $P_{t}$ scale (\%)

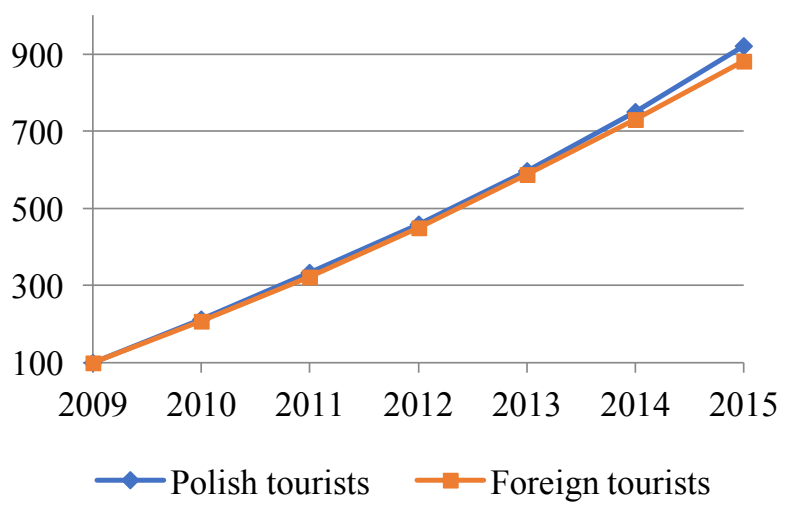

Source: Own study based on table 3.2 .

Polish tourists, the velocity of the process increased from 2009 to 2015, but a little more slowly from the year 2010 to 2012. However, in the case of foreign tourists the velocity of the process grew gradually from 2009 - 2012, and then decreased in the years $2012-$ 2015. In the year 2012 certain hindering factors were observed. By analyzing the continuous processes, both on an absolute $\left(M_{t}\right)$ and on a relative percentage scale $\left(P_{t}\right)$ one can see a big difference in the dynamics of growth between the number of foreign and Polish tourists, with the latter of the two groups showing the higher dynamics. In general, dynamics of change of Polish residents was higher than non-residents in the years 2009-2015, but in the year 2012, the value of growth of non-residents was more dynamic than Polish residents value. 


\section{Conclusion}

Continuous sets, particularly when expressed in a relative scale (in percentages) allows us to see the dynamics of economic processes in much better way. In the studied case, the discrete sets, converted to continuous sets clearly show the difference in the dynamics of growth between the number of Polish residents and non-residents overnight visitors who stayed in Polish hotels between 2009 and 2015.

When comparing the dynamics of the processes for the discrete as well as continuous values, on an absolute and a relative scale, one can notice a general upward trend in both cases, even in spite of the drop in 2012. It can also be noticed that the dynamics of growth in the number of Polish tourists is slightly higher than that in the number of foreign tourists. This reflects the increasing participation of Poles in the domestic market. This trend will probably keep up in the years to come due to the fact that the dynamics of Poland's economic growth is much higher than in the other EU countries. In the year 2012, however, the value of change of non-residents was more dynamic than Polish residents value. This was due to the sports event in Poland in 2012. European Football Championship was organized that time.

\section{References}

Abraham-Frois G. (2002). Dynamique Economique, PrécisDalloz, 9 édition, Paris.

Central Statistical Office (2015). Tourism in 2014, Statistical Information and Elaboration, Social Surveys and Living Conditions Department, Warszawa.
Central Statistical Office (2016). Tourism in 2015, Statistical Information and Elaboration, Social Surveys and Living Conditions Department, Warszawa.

Kondratowicz-Pietruszka E., Stokłosa K. (1994). Wybrane zagadnienia kinetyki procesów ekonomicznych, Wydawnictwo AE w Krakowie, Kraków.

Łuka P., (2007). Dynamika wzrostu liczby osób korzystajacych $z$ krajowych połaczeń lotniczych $w$ Polsce $w$ latach 2002-2005, Ekonomia i Nauki Humanistyczne z. 16, Zeszyty Naukowe Politechniki Rzeszowskiej Nr 235, Rzeszów.

Łuka P., Kwiatkowska-Sienkiewicz K. (2010a). Kinetic analysis of quality, utility and price changes of the second-hand cars in Poland, Annals of the Ovidius University, Economic Science Series, Volume XV.

Luka P., Kwiatkowska-Sienkiewicz K. (2010b). Quality and utility estimation of the second-hand cars, Current trends in commodity science. Selected quality problems, Zeszyty Naukowe UE w Poznaniu nr 160, Poznań.

Łuka P., Łuka M. (2002). Analiza działalności hotelarskiej $w$ Polsce $w$ latach 1994-1999, Ekonomia i Nauki Humanistyczne, z. 11, Zeszyty Naukowe Politechniki Rzeszowskiej Nr 201, Rzeszów.

Stokłosa K. (2006). Krytyka wspótczesnych metod oceny dynamiki procesów w ekonomii i w zarządzaniu, praca zbiorowa pod redakcją naukową M. Trockiego i S. Gregorczyka, SGH w Warszawie, Warszawa.

Stokłosa K.(2004). Krytyka wspótczesnych metod oceny $i$ porównań dynamiki procesów ekonomicznych, Materiały Konferencji Naukowej Politechniki Radomskiej, Radom. 